\title{
Protocol of a Randomized Controlled Study of the PneumRx Endobronchial Coil System versus Standard-of-Care Medical Management in the Treatment of Subjects with Severe Emphysema (ELEVATE)
}

\author{
Felix J.F. Herth ${ }^{a}$ Dirk-Jan Slebos ${ }^{b, c}$ Pallav L. Shah ${ }^{d, e}$ Martin Hetzel $^{f}$ \\ Gerald Schmid-Bindert ${ }^{\mathrm{g}} \mathrm{h} \quad$ Adam S. LaPrad $^{\mathrm{i}}$ Gaëtan Desléej $^{\mathrm{j}}$ Arschang Valipourk $^{\mathrm{k}}$ \\ aThoraxklinik and Translational Lung Research Center (TLRC), University of Heidelberg, Heidelberg, Germany; \\ ${ }^{b}$ Department of Pulmonary Diseases, University Medical Center Groningen, University of Groningen, Groningen, \\ The Netherlands; ${ }^{c}$ Groningen Research Institute for Asthma and COPD, University Medical Center Groningen, University \\ of Groningen, Groningen, The Netherlands; ${ }^{\mathrm{d}}$ Royal Brompton Hospital and Chelsea and Westminster Hospital, London, \\ UK; ${ }^{\mathrm{e}}$ National Heart and Lung Institute, Imperial College, London, UK; ${ }^{f} \mathrm{Krankenhaus} \mathrm{vom} \mathrm{Roten} \mathrm{Kreuz,} \mathrm{Stuttgart,}$

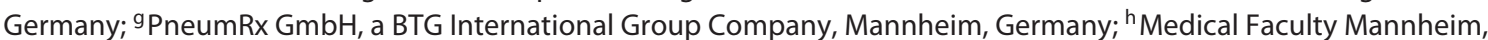 \\ Heidelberg University, Mannheim, Germany; i PneumRx, Inc., a BTG International Group Company, Santa Clara, CA, \\ USA; ${ }^{j}$ University Hospital of Reims, INSERM U1250, Reims, France; ${ }^{k}$ Karl-Landsteiner-Institute for Lung Research and \\ Pulmonary Oncology, Department of Respiratory and Critical Care Medicine, Krankenhaus Nord-Klinik Floridsdorf, \\ Vienna, Austria
}

\section{Keywords}

Bronchoscopy · Emphysema · Endobronchial coils · Lung volume reduction

\begin{abstract}
Background: The PneumRx endobronchial coil system for patients with severe emphysema has been shown to improve quality of life, exercise capacity, and pulmonary function in patients with emphysema. A post hoc analysis of the RENEW trial has identified patient characteristics and lobar selection methods associated with improved outcomes, which have to be confirmed prospectively. Methods: The ELEVATE trial is a prospective, multicenter, open label, randomized (2:1), controlled trial comparing outcomes in patients treated with endobronchial coils (treatment) to a medically managed control group (control). The trial aims to enroll 210 patients (140 in the treatment group and 70 in the
\end{abstract}

\begin{tabular}{ll}
\hline KARGER & $\begin{array}{l}\text { ( } 2019 \text { The Author(s) } \\
\text { Published by S. Karger AG, Basel }\end{array}$ \\
E-Mail karger@karger.com & This article is licensed under the Creative Commons Attribution- \\
www.karger.com/res & NonCommercial-NoDerivatives 4.0 International License (CC BY- \\
& NC-ND) (http://www.karger.com/Services/OpenAccessLicense). \\
Usage and distribution for commercial purposes as well as any dis- \\
tribution of modified material requires written permission.
\end{tabular}

control group) with severe emphysema. Control patients will be eligible to crossover to coil treatment after 6 months of follow-up. The co-primary effectiveness endpoints are percent change in forced expiratory volume in $1 \mathrm{~s}$ and quality of life measured by change in St. George's Respiratory Questionnaire from baseline to 6 months. Secondary objectives are determination of responder rates of clinical endpoints and mean change in other functional and physiologic endpoints. All patients will be followed for 24 months after initial treatment. Adverse events will be collected on an ongoing basis throughout the trial. Discussion: The primary objective of the ELEVATE trial is to prospectively confirm the safety and effectiveness profile of the coil system for the treatment of severe emphysema in consideration of the findings of previous randomized controlled trials. Secondary objectives are the determination of responder rates in all clinical endpoints and mean change in physiologic endpoints.

(C) 2019 The Author(s)

Published by S. Karger AG, Basel

Assoc. Prof. Arschang Valipour, MD

Krankenhaus Nord-Klinik Floridsdorf Brünnerstrasse 68

AT-1210 Vienna (Austria)

E-Mail arschang.valipour@wienkav.at 


\section{Introduction}

The estimated global prevalence of emphysema is $1.8 \%$ [1]. Upon disease progression, patients with emphysema develop hyperinflation with an increase in residual volume (RV) and total lung capacity (TLC) caused by the gradual destruction of alveolar walls and loss of the lung's natural elastic recoil which results in the collapse of unsupported airways during exhalation. Eventually, patients develop hypoxemia and deconditioning that contribute to muscle weakness and fatigue. The crippling effects of end-stage emphysema include severe dyspnea, severe limitation of activities, depression/anxiety, recurrent exacerbation, and ultimately respiratory failure, which may finally result in death [2].

There are limited treatment options for patients with severe emphysema that include medications, pulmonary rehabilitation, supplemental oxygen, and surgical procedures (lung transplantation and lung volume reduction surgery [LVRS]) [2]. Since the NETT (National Emphysema Treatment Trial) [3], which established the concept of LVRS, many clinical trials have demonstrated the effect of lung volume reduction leading to a significant improvement in lung function, exercise capacity, and quality of life (QoL) [4]. However, due to the increased risk of morbidity and mortality associated with thoracic surgery $[4,5]$, the lack of sufficient organ donors, and as not all patients are eligible for LVRS, there is an unmet need for minimally invasive therapies to reduce lung volume in hyperinflation. Recent years have seen the development of various techniques for endoscopic lung volume reduction [6], including endobronchial valves [7-9], coils [10], bronchoscopic thermoablation [11], and biological lung volume reduction with a sealant [12]. Post hoc analyses of VENT (Endobronchial Valve for Emphysema Palliation Trial) and subsequent prospective randomized studies identified complete occlusion of the treated lobe with absence of collateral ventilation to be a strong predictor of response to endobronchial valve therapy $[8,9,13-18]$. Collateral ventilation, however, is a common status in emphysema patients, with a prevalence of $50-90 \%$ depending on the lung [19]. The high screening failure rates in clinical trials of valve therapy thus demonstrate a need for alternative, complementary treatment options: for example, in the LIBERATE study [18], out of 909 patients that consented to participate in the study, 190 were finally randomized. Patients who are not candidates for valve therapy might be eligible for coil treatment.

In the RENEW trial, participants were randomly assigned to receive either bilateral coil treatment involving

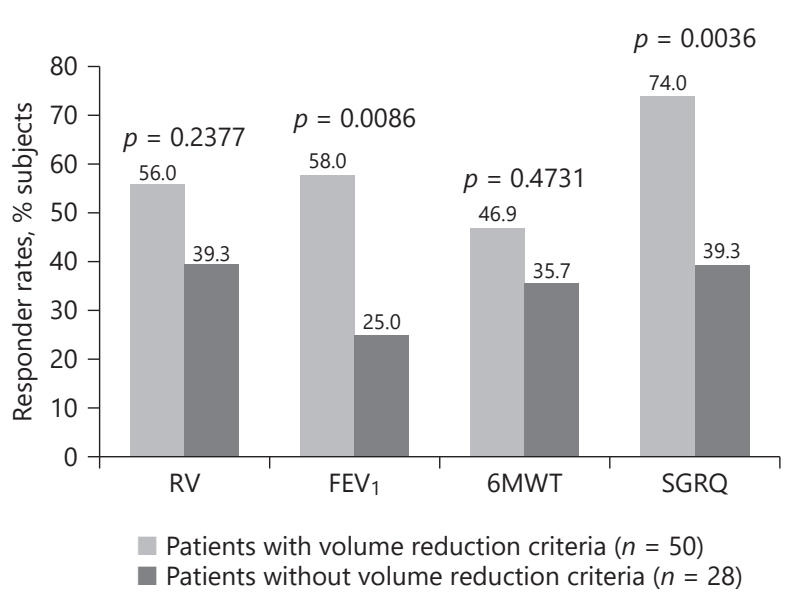

Fig. 1. Responder rates in patients with and without identified predictive criteria for response. Volume reduction criteria were "no airway disease," low attenuation area $\geq 20 \%$, residual volume (RV) $\geq 200 \%$ of predicted. Patients who met those criteria had significantly higher response rates in clinical endpoints, using standard minimum clinical important differences: RV $-350 \mathrm{~mL}$, forced expiratory volume in $1 \mathrm{~s}\left(\mathrm{FEV}_{1}\right) 10 \%, 6$-min walking test (6MWT) 26 m, St. George's Respiratory Questionnaire (SGRQ) -4 points. Both subgroups were treated in the most damaged lobes as measured by quantitative CT analysis. Reprinted from Slebos et al. [21] with permission of Elsevier.

2 sequential procedures in which 10-14 coils were bronchoscopically placed in a single lobe of each lung or usual care alone. The study demonstrated statistically significant improvements in exercise capacity and QoL in patients treated with endobronchial coils; however, improvements in exercise capacity in the intent-to-treat (ITT) population were considered modest and of uncertain clinical importance $[20,21]$. Recently, post hoc anal$y$ sis of the RENEW trial established patient baseline characteristics and lobe selection criteria that are associated with improved outcomes following endobronchial coil treatment [21]. Patients identified as responders in this post hoc analysis had higher emphysema scores (\% low attenuation area [LAA] at -950 Hounsfield units [HU]), a baseline RV of at least $200 \%$ of predicted, and absence of significant airway disease in high-resolution computed tomography (HRCT), as identified by independent reviewers. In addition, quantitative computed tomography (QCT) analysis was shown to be important in determining the lobe with the greatest ipsilateral emphysema score, especially in patients with homogeneous emphysema [22, 23]. Treatment of lobes according to this QCT criterion 
Table 1. The ELEVATE trial inclusion criteria

- Read, understood, and signed the informed consent form

- Meets indications for use per IFU

- Bilateral heterogeneous and/or homogeneous emphysema

- $\quad 15 \%$ predicted $\leq \mathrm{FEV}_{1}$ after bronchodilation $\leq 45 \%$ predicted

- RV after bronchodilation $\geq 200 \%$ predicted

- $\quad$ TLC after bronchodilation $>100 \%$ predicted

- RV/TLC after bronchodilation $>55 \%$

- Dyspnea $\geq 2$ on mMRC dyspnea scale despite optimal medical management

- Receiving optimal drug therapy and medical management according to clinical practice

- Performing regular physical activity at least twice/week

- Stopped smoking as confirmed by $\mathrm{CoHb}$

- $100 \mathrm{~m} \leq 6 \mathrm{MWT} \leq 450 \mathrm{~m}$

- Deemed eligible per ERC

The World Health Organization defines physical activity as any bodily movement produced by skeletal muscles that requires energy expenditure - including activities undertaken while working, playing, carrying out household chores, traveling, and engaging in recreational pursuits. For those with limited mobility, this should be done at least 2 days per week. There was no specific duration of smoking cessation required in the protocol, but those with a $\mathrm{CoHb}$ level $<2.5 \%$ were defined as nonsmokers. $6 \mathrm{MWT}$, 6-min walking test; $\mathrm{CoHb}$, carboxyhemoglobin; ERC, Eligibility Review Committee; $\mathrm{FEV}_{1}$, forced expiratory volume in $1 \mathrm{~s}$; IFU, instructions for use; mMRC, modified Medical Research Council; RV, residual volume; TLC, total lung capacity.

was associated with significant improvement in lobar volume reduction 12 months after coil treatment [21].

From the RENEW post hoc analysis, both visual and QCT methods as well as traditional baseline pulmonary function tests appear to be important to maximize response to endobronchial coil treatment (Fig. 1). Based on these findings, the ELEVATE trial was designed to confirm the patient group most likely to respond to coil system treatment.

\section{Materials and Methods}

\section{Study Design}

The ELEVATE trial (ClinicalTrials registration No. NCT0336039) is a prospective, multicenter, open-label, randomized, controlled trial comparing outcomes in patients treated with endobronchial coils (treatment group) to a medically managed control group (control group). Since this is an open-label study, there will be no sham procedure in the control group. A total of 210 patients will be randomized in a 2:1 ratio of treatment to control, respectively (140 patients in the treatment group and 70 patients in the control group), in up to 30 sites across Europe (there are some regional protocol amendments based on authority requirements regarding follow-up or radiation protection) with a minimum of 82 subjects determined to have bilaterally heterogeneous emphysema, defined as $\geq 15 \%$ difference in LAA at $-950 \mathrm{HU}$ between ipsilateral lobes analyzed by QCT software in both lungs, respectively (Tables 1,2$)$. All patients will be stratified by site and emphysema heterogeneity: each site will be allocated the same percentage of patients in the treatment or control arm, and also with heterogeneous or homogeneous emphysema. The process of eligibility is described in detail below (see Screening Assessment). Once the patient fulfills all inclusion criteria and is accepted by the Eligibility Review Committee (ERC) (Fig. 3), the randomization, which is activated by the investigator, is automated and built into the electronic case report form. Randomization will be determined using assignment by a computer-generated randomization scheme.

All patients randomized to treatment will be followed for 24 months after the initial treatment. Control group patients will be eligible for treatment with coils (crossover) 6 months after randomization, at which point they will be evaluated for crossover. Crossover patients will then be followed for 24 months after coil treatment.

\section{Screening Assessments}

The study population will include patients with severe emphysema indicated for coil treatment per the approved, CE-marked instructions for use who meet the inclusion/exclusion criteria (Tables 1,2). A completed patient informed consent form will be required from all participating patients. The informed consent form will be reviewed and approved by the ethics committees of all participating sites. The study will be conducted in accordance with Good Clinical Practice guidelines, and all applicable country, state, and local regulations.

\section{Assessing HRCT for Inclusion Criteria}

In prior coil studies, the most damaged lobe was defined visually either by the physician or a core lab. In ELEVATE, QCT analysis will assess the degree of emphysematous lung tissue (LAA) in the HRCT. The threshold for this analysis is defined as $<-950 \mathrm{HU}$. This analysis will be used to identify the most destroyed lobe in the right and left lungs, which will be the target lobes for treatment. BTG/PneumRx will provide sites with an anonymized lung densitometry report that will identify lobar volumes and the degree of destruction (LAA) based on $-950 \mathrm{HU}$ for each lobe (Fig. 2).

In addition, all HRCT scans will be reviewed by an independent Radiology Review Committee (RRC) composed of expert radiologists who will perform a comprehensive assessment of the HRCT of features relevant for endobronchial coil therapy. The RRC will assess and describe the following morphological signs in the lung: emphysema distribution (centrilobular, panlobular, paraseptal), airway wall thickening, bronchiectasis, inflammatory small airway disease, mucous plugging, imaging consistent with active pulmonary infection, significant interstitial or pleural disease, significant bullae, nodules or other lung pathologies, radiographic confirmation of atelectasis, or other scarring/fibrosis in areas of intended coil implant.

The report from the RRC will be provided to the ERC who will approve the eligibility of each patient (Fig. 3). The ERC consists of 5 experienced interventional pulmonologists who are experts in lung volume reduction procedures and patient selection [21]. This 
committee will confirm eligibility and suitability of patients selected for participation in the ELEVATE trial. The ERC and RRC serve as a virtual multidisciplinary team, to assure consistency in patient selection. A complete treatment includes 2 procedures, approximately 2 months apart, providing bilateral treatment to the most destroyed lobe of each lung. A detailed description of the state-of-the-art treatment has recently been published by Slebos et al. [10].

\section{Primary and Secondary Endpoints}

The objective of the study is to prospectively confirm the safety and effectiveness profile of coil treatment in consideration of the findings of previous randomized controlled trials [20, 21]. The coprimary endpoints are the percent change in $\mathrm{FEV}_{1}$ and change in the St. George's Respiratory Questionnaire (SGRQ) from baseline to 6 months. The secondary endpoints are determination of responder rates in clinical endpoints and mean change in physiologic endpoints. Responder rate at 6 months is defined as percent of patients that achieve 2 or more of the following minimum clinical important differences; a change from baseline in the 6-min walking test $(6 \mathrm{MWT}) \geq 26 \mathrm{~m} \mathrm{[24]}$, SGRQ $\leq-4$ points [25], $\mathrm{FEV}_{1} \geq 10 \%$ [26], or RV $\leq-350 \mathrm{~mL}$ [27]. A complete list of endpoints is shown in Table 3.

Assessment visits are displayed in Table 4 for both the treatment group and the control group.

\section{Statistical Analysis}

All effectiveness parameters will be analyzed on the ITT population through the 6-month visit, with missing data imputed using Markov chain Monte Carlo multiple imputation. Comparisons will be considered significant at a two-sided a level of 0.05 . Comparisons between treatment groups for the co-primary effectiveness endpoints will be conducted using analysis of covariance with factors of treatment, site, and emphysema heterogeneity as well as a covariate of corresponding baseline values. Mean differences between treatments and corresponding two-sided 95\% confidence intervals (CIs) will be calculated.

For continuous secondary and other effectiveness endpoints, treatment comparisons will be conducted using the same methods as for the co-primary endpoints. For responder endpoints, treatment groups will be compared using logistic regression with factors of treatment, site, and heterogeneity as well as a covariate of corresponding baseline values. Odds ratios (ORs) with corresponding 95\% CIs will be computed as well as response rates for each treatment group. In addition, the results of the EuroQol-5 dimension QoL questionnaire (EQ-5D) will be summarized by shift tables for each dimension.

For continuous effectiveness endpoints with significant deviations from normality, treatment groups will be compared using a nonparametric rank-transformed analysis of covariance as the primary analysis, and median differences will be computed.

Subgroup analysis for primary and secondary effectiveness measures will include a comparison of results by disease distribution (bilateral heterogeneous, bilateral homogeneous, and mixed) as defined per QCT (heterogeneous defined by $\geq 15 \%$ ipsilateral difference in \%LAA at $-950 \mathrm{HU}$ ) and RV at baseline of $200-225$ or $>225 \%$.

Sample size was selected based on RENEW post hoc analyses to provide $\geq 85 \%$ power to detect a difference of $10 \%$ in mean percent change in $\mathrm{FEV}_{1}$ and -7 points in mean change in SGRQ between treatment and control groups simultaneously as co-primary
Table 2. The ELEVATE trial exclusion criteria

- Meets any of the contraindications listed in the instructions for use

- Primary diagnosis of asthma

- Two or more exacerbations of chronic obstructive pulmonary disease (COPD) in the prior year, or 1 or more COPD exacerbations in the prior 3 months with indication for hospitalization assessment according to GOLD 2017 recommendations

- Predominant small-airway disease defined as significant bronchiectasis with sputum production ( $>2$ tablespoons daily) or significant bronchial wall thickening per high-resolution CT

- Percent low attenuation area $<20 \%$ in the most damaged lobe of either lung

- CT imaging consistent with active pulmonary infection, significant interstitial disease, or pleural disease (predominant bulla $>8 \mathrm{~cm}$ or $1 / 3$ hemithorax), or severe bullous or predominant paraseptal emphysema pattern

- Lung pathology of nodule not proven stable or benign

- Radiographic confirmation of atelectasis or other scarring/ fibrosis in areas of intended coil implantation

- Use of $>10 \mathrm{mg} /$ day prednisolone or equivalent dosage of a different corticosteroid

- Severe pulmonary hypertension (right ventricular systolic pressure $>50 \mathrm{~mm} \mathrm{Hg}$ or other signs of pulmonary hypertension with right ventricular dysfunction)

- Severe hypercapnia $\left(\mathrm{PaCO}_{2}>55 \mathrm{~mm} \mathrm{Hg}\right.$ on room air $)$ and/or severe hypoxemia $\left(\mathrm{PaO}_{2}<45 \mathrm{~mm} \mathrm{Hg}\right.$ on room air, high altitude criterion: $\mathrm{PaO}_{2}<30 \mathrm{~mm} \mathrm{Hg}$ )

- Previous lung volume reduction (LVR) surgery, lung transplantation, lobectomy, LVR devices, or other device to treat COPD in either lung

- Diagnosed with $\alpha_{1}$-antitrypsin deficiency

- Diffusing capacity of the lung for CO $<20 \%$

- Significant, recent, or unstable cardiac disease defined as severe heart failure (left ventricular ejection fraction $<45 \%$ despite optimal medical management), unstable cardiac arrhythmia, or coronary artery disease (angina on activity), or ischemic event in the past 6 months

- $\quad$ Body mass index $>30$

GOLD, Global Strategy for the Diagnosis, Management, and Prevention of COPD, Global Initiative for Chronic Obstructive Lung Disease (GOLD) 2017. 


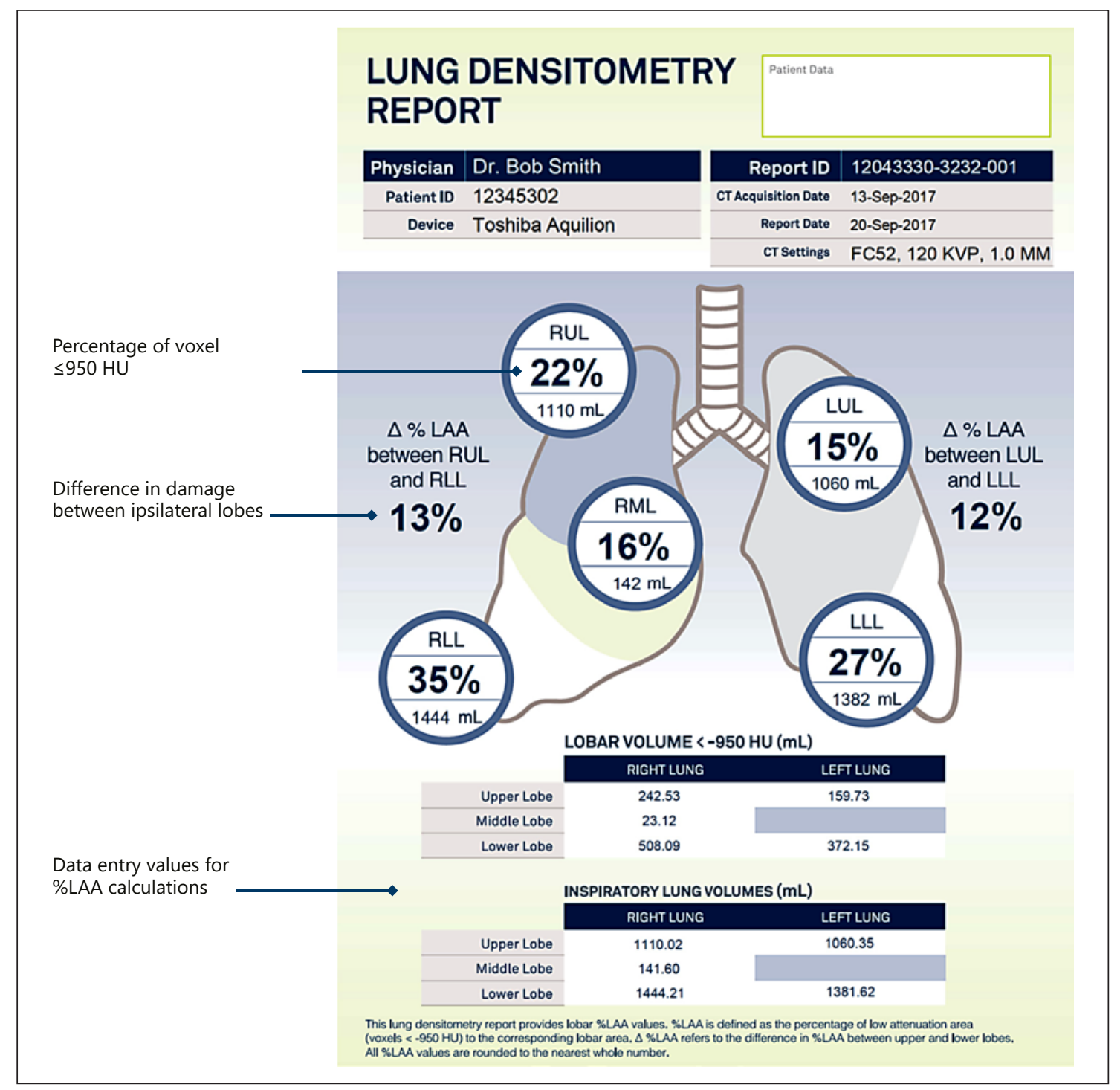

Fig. 2. Sample densitometry report.

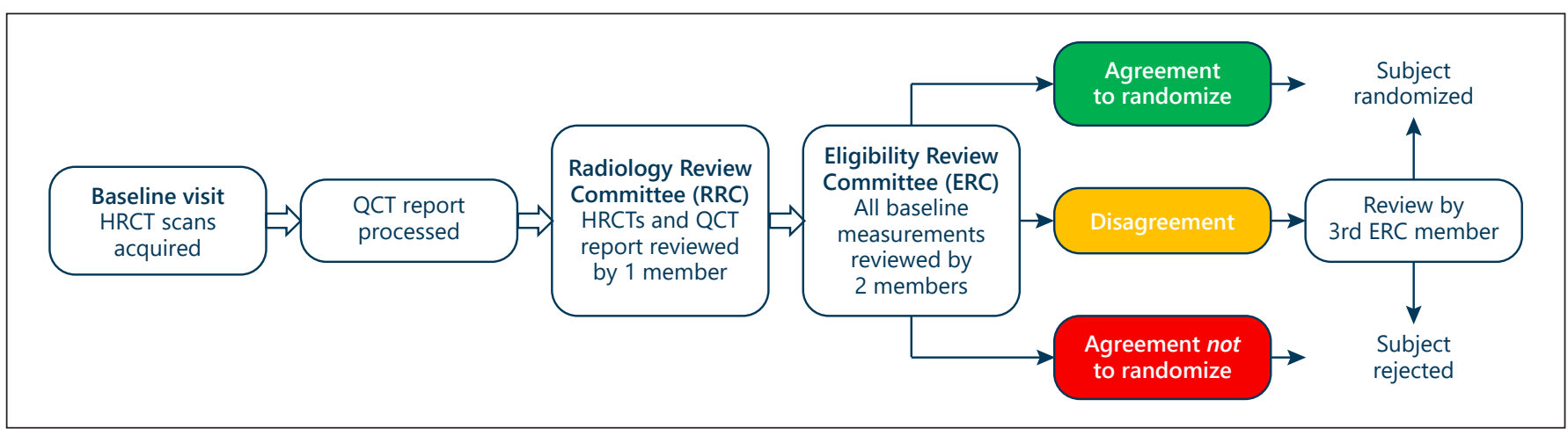

Fig. 3. Eligibility workflow. Patient must have $\mathrm{T} \times 2$ visit $\leq 45$ days from baseline visit. Study goal is 16 days (ERC agreement) and 30 days (ERC agreement) for randomization to accommodate site scheduling.

Herth/Slebos/Shah/Hetzel/SchmidBindert/LaPrad/Deslée/Valipour 
Table 3. Study endpoints

\begin{tabular}{|c|c|c|}
\hline Co-primary effectiveness endpoint & Secondary endpoints & Other effectiveness endpoints \\
\hline $\begin{array}{l}\text { Percent change in } \mathrm{FEV}_{1} \\
\text { from baseline to } 6 \text { months }\end{array}$ & $\begin{array}{l}\text { Responder rate at } 6 \text { months defined as percent of } \\
\text { subjects that achieve } 2 \text { or more of the following } \\
\text { MCIDs }\end{array}$ & $\begin{array}{l}\text { Changes in other pulmonary function } \\
\text { measures (RV, RV/TLC, } \mathrm{FEV}_{1}, \mathrm{FEV}_{1} / \\
\text { FVC) }\end{array}$ \\
\hline Change in SGRQ from baseline to 6 months & $\begin{array}{l}\text { Change from baseline in: } \\
\quad 6 \mathrm{MWT} \geq 26 \mathrm{~m}[13] \\
\quad \mathrm{SGRQ} \leq-4 \text { points }[14] \\
\mathrm{FEV}_{1} \geq 10 \%[15] \\
\mathrm{RV} \leq-350 \mathrm{~mL}[16] \\
\text { - Change in mean expiratory target lobar volume } \\
\text { measured by HRCT (lobar RV) from baseline to } \\
6 \text { months } \\
\text { - Change in VC as measured by plethysmography } \\
\text { from baseline to } 6 \text { months }\end{array}$ & $\begin{array}{l}\text { - Change in exercise capacity } \\
\text { (6MWT) } \\
\text { - Mean change at } 6 \text { months for CAT } \\
\text { and EQ5D } \\
\text { - Individual MCID responders at } 6 \\
\text { months for } 6 \mathrm{MWT} \text {, SGRQ, and FEV } 1 \\
\text { as defined above } \\
\text { - Responder rate at } 6 \text { months defined } \\
\text { as percent of subjects that achieve } \\
\text { FEV } 1212 \% \\
\text { - Responder rate at } 6 \text { months defined } \\
\text { as percent of subjects that achieve } \\
\text { SGRQ } \leq-8 \text { points }\end{array}$ \\
\hline
\end{tabular}

6MWT, 6-min walking test; CAT, COPD assessment test; EQ-5D, EuroQol-5 dimensions quality of life questionnaire; FEV 1 , forced expiratory volume in $1 \mathrm{~s}$; HRCT, high-resolution CT; lobar RV, mean expiratory lobar volume of the treated lobes calculated via quantitative CT analysis of the expiratory HRCT scans; MCID, minimum clinical important difference; RV, residual volume; SGRQ, St. George's respiratory questionnaire; TLC, total lung capacity; VC, vital capacity.

Table 4. Patient schedule

\begin{tabular}{c|c|c|}
\hline \multicolumn{2}{c|}{ Baseline visit } \\
\hline \multicolumn{4}{|c|}{ Randomization $(2: 1)$} \\
\hline Treatment group & \\
\hline
\end{tabular}

First coil treatment ( $<45$ days from baseline)

Phone call visit 1 ( 1 week after first coil treatment)

1 month after first coil treatment

Second coil treatment (2 months after first procedure)

Phone call visit 2 ( 1 week after second coil treatment)

1 month after second coil treatment

Phone call visit 3 (4.5 months after first coil treatment)

6-month follow-up

12-month follow-up

24-month follow-up
Phone call visit 1 (1 week after randomization)

Phone call visit 2 (2 months after randomization)

Phone call visit 3 (4.5 months after randomization) 6 months after baseline visit

First coil treatment (<30 days after 6-month visit)

Phone call visit 4 ( 1 week after first coil treatment)

1 month after first coil treatment

Second coil treatment (2 months after first procedure)

Phone call visit 5 ( 1 week after second coil treatment)

1 month after second coil treatment

Phone call visit 6 ( 4.5 months after first coil treatment)

6-month follow-up

12-month follow-up

24-month follow-up 
endpoints (e.g., $90 \%$ power for percent change in $\mathrm{FEV}_{1}$ and $>95 \%$ power for change in SGRQ such that co-primary power $\geq 90 \% \times$ $95 \%=85 \%)$. One hundred and forty subjects in the treatment group and 70 subjects in the control group are required, assuming a SD of 20 and 12 for percent change in $\mathrm{FEV}_{1}$ and change in SGRQ, respectively, using a 2 -sample $t$ test and a two-sided a level of 5\%, allowing for a dropout rate of up to $9 \%$. A sample size modification will be considered after $50 \%$ of patients have completed the 6-month follow-up visit by evaluating the co-primary effectiveness endpoints using the promising zone sample size re-estimation method of Mehta and Pocock [28].

\section{Safety}

An independent data safety monitoring board (DSMB) will oversee the conduct of the study. The DSMB will review and evaluate serious adverse events on an "as needed" basis as requested by the sponsor and all reported adverse events at minimum on a quarterly basis. The committee may recommend a temporary hold or discontinuation of the study in the event of the occurrence of serious or unexpected adverse events that are determined by the DSMB to pose a significant safety concern.

\section{Discussion}

Coil placement has demonstrated effectiveness and an acceptable safety profile in multiple clinical trials [20, 29-34]. All randomized controlled trials reached their primary endpoints with statistical significance. A recent 2-year follow-up of the REVOLENS (Réduction volumique endobronchique par spirales) trial showed sustained response in QoL and no unexpected safety events [35]. However, improvements in exercise capacity $(6 \mathrm{MWT})$ and lung function $\left(\mathrm{FEV}_{1}\right)$ in the RENEW trial were considered to be rather modest. The initial RENEW analysis has shown greater treatment effects in the subgroup with a baseline RV $>225 \%$. Further analyses were done to explore potential predictors of better clinical outcomes [21]. These post hoc analyses identified a patient subgroup that achieved statistically clinically meaningful improvements in pulmonary function and volume reduction outcomes 12 months after coil treatment [21]. These patients had higher emphysema scores (>20\% LAA), higher baseline RV (>200\%), and absence of significant airway disease. In fact, a recent meta-analysis including almost 2,800 patients with emphysema who underwent either a surgical or endoscopic lung volume reduction procedure confirmed a high correlation between the degree of volume reduction and relevant outcomes of obstructive pulmonary disease (COPD), such as $\mathrm{FEV}_{1}, 6 \mathrm{MWT}$, and QoL (SGRQ) [4]. The ELEVATE trial thus has been designed with patient inclusion and exclusion criteria that take the pa- tient selection findings from the RENEW post hoc analysis into account. In addition, both an RRC and an ERC are used to identify patients with severe emphysema that would most likely benefit from coil therapy. The inevitable limitation of this study, however, is the openlabel design. Given that coils are visible on X-ray (which is required during the postprocedural follow-up) and patients frequently experience mild hemoptysis following the procedure, unblinding physicians and/or patients was deemed not practicable for this particular technology.

Finally, although patient selection criteria remain crucial for treatment success, different safety profiles of the available therapies must also be taken into consideration. While the most common adverse event for valve therapy is pneumothorax, with a rate as high as $30 \%[16,17]$, the most common side effects of coil therapy are pneumonia (18\% in the RENEW trial) and COPD exacerbations ( $26 \%$ in the RENEW trial), whereas the pneumothorax rates following coil insertion are substantially lower with an incidence of $6-10 \%[10,20,29]$. In comparison to endoscopic lung volume reduction techniques, patients undergoing lung volume reduction surgery appear to have substantially higher complication rates overall. In an analysis of the NETT results, Criner and Sternberg [36] reported a $60 \%$ incidence of at least 1 complication within 30 days of surgery, $21 \%$ of patients required at least 1 reintubation, and $11 \%$ were readmitted to the intensive care unit. Furthermore, close to $40 \%$ of patients had a prolonged air leak of $>7$ days.

\section{Conclusions}

Patients with severe emphysema have limited treatment options. Endobronchial coils may provide a minimally invasive alternative for these patients. Endobronchial coils have demonstrated improved exercise capacity and QoL with a sustained benefit over 2 years for some patients $[20,35]$. The ELEVATE trial aims to establish more sophisticated patient selection criteria that will identify those patients that are most likely to benefit from endobronchial coils. The objective of the study is to prospectively confirm the safety and effectiveness profile of the coil system for the treatment of severe emphysema in consideration of the findings of previous randomized controlled trials. Secondary objectives are the determination of responder rates to clinical endpoints and mean change in physiologic endpoints. 


\section{Statement of Ethics}

The study required a completed patient informed consent form from all participating patients, which was reviewed and approved by the ethics committees of all participating sites. The study was conducted in accordance with Good Clinical Practice guidelines, and all applicable country, state, and local regulations.

\section{Disclosure Statement}

F.J.F.H. received fees for adboard and consultancy activities for BTG. A.S.L. and G.S.-B. are employees of PneumRx/BTG. M.H. received speaker fees and consultancy fees from PneumRx. D.-J.S. is a physician advisor and consultant for PneumRx/BTG and was PI of several clinical trials for PneumRx/BTG. G.D. received speaker fees and consultancy fees from BTG/PneumRx. P.L.S. received personal fees for consultancy activities and lecture fees from BTG/ PneumRx. A.V. has received speaker fees from PneumRx Inc.

\section{Funding Sources}

This study is sponsored by PneumRx Inc., USA. The authors of this manuscript did not receive any reimbursement or fees for their contributions to this article.

\section{Author Contributions}

All authors contributed to the design of the ELEVATE trial and to writing and revising this manuscript. F.J.F.H. and A.V. are the principal investigator and co-principal investigator. F.J.F.H., A.V., D.-J.S., P.L.S., and G.D., and are also the members of the ERC, which is described in the paper.

\section{References}

1 Halbert RJ, Natoli JL, Gano A, Badamgarav E, Buist AS, Mannino DM. Global burden of COPD: systematic review and meta-analysis. Eur Respir J. 2006 Sep;28(3):523-32.

2 Global Initiative for Chronic Obstructive Lung Disease (GOLD). 2019 Global Strategy for Prevention, Diagnosis and Management OF COPD [cited $2019 \mathrm{Feb} 5$ ]. Available from: https://goldcopd.org/wp-content/uploads/2018/11/GOLD-2019-v1.7-FINAL14Nov2018-WMS.pdf.

3 Fishman A, Martinez F, Naunheim K, Piantadosi S, Wise R, Ries A, et al.; National Emphysema Treatment Trial Research Group. A randomized trial comparing lung-volume-reduction surgery with medical therapy for severe emphysema. N Engl J Med. 2003 May; 348(21):2059-73.

4 van Geffen WH, Slebos DJ, Herth FJ, Kemp SV, Weder W, Shah PL. Surgical and endoscopic interventions that reduce lung volume for emphysema: a systemic review and metaanalysis. Lancet Respir Med. 2019 Apr;7(4): 313-24.

5 Minervini F, Kestenholz PB, Paolini V, Pesci A, Libretti L, Bertolaccini L, et al. Surgical and endoscopic treatment for COPD: patients selection, techniques and results. J Thorac Dis. 2018 Oct;10(S27 Suppl 27):S3344-51.

6 Herth FJ, Slebos DJ, Criner GJ, Valipour A, Sciurba F, Shah PL. Endoscopic Lung Volume Reduction: An Expert Panel Recommendation - Update 2019. Respiration. 2019;97(6): 548-57.

7 Slebos DJ, Shah PL, Herth FJ, Valipour A. Endobronchial valves for endoscopic lung volume reduction: best practice recommendations from expert panel on endoscopic lung volume reduction. Respiration. 2017;93(2):138-50.
8 Hartman JE, Vanfleteren LE, van Rikxoort EM, Slebos DJ; on behalf of the SOLVE consortium. Bronchoscopic Lung Volume Reduction Treatment Using Endobronchial Valves for Emphysema: emerging Questions. Respiration. 2018;96(6):588-9.

9 Klooster K, Hartman JE, Ten Hacken NH, Slebos DJ. One-Year Follow-Up after Endobronchial Valve Treatment in Patients with Emphysema without Collateral Ventilation Treated in the STELVIO Trial. Respiration. 2017;93(2):112-21.

10 Slebos DJ, Ten Hacken NH, Hetzel M, Herth FJF, Shah PL. Endobronchial Coils for Endoscopic Lung Volume Reduction: Best Practice Recommendations from an Expert Panel. Respiration. 2018;96(1):1-11.

11 Gompelmann D, Shah PL, Valipour A, Herth FJF. Bronchoscopic Thermal Vapor Ablation: Best Practice Recommendations from an Expert Panel on Endoscopic Lung Volume Reduction. Respiration. 2018;95(6):392-400.

12 Milenkovic B, Janjic SD, Popevic S. Review of lung sealant technologies for lung volume reduction in pulmonary disease. Med Devices (Auckl). 2018 Jun;11:225-31.

13 Sciurba FC, Ernst A, Herth FJ, Strange C, Criner GJ, Marquette CH, et al.; VENT Study Research Group. A randomized study of endobronchial valves for advanced emphysema. N Engl J Med. 2010 Sep;363(13):1233-44.

14 Klooster K, ten Hacken NH, Hartman JE, Kerstjens HA, van Rikxoort EM, Slebos DJ. Endobronchial Valves for Emphysema without Interlobar Collateral Ventilation. N Engl J Med. 2015 Dec;373(24):2325-35.

15 Davey C, Zoumot Z, Jordan S, McNulty WH, Carr DH, Hind MD, et al. Bronchoscopic lung volume reduction with endobronchial valves for patients with heterogeneous emphysema and intact interlobar fissures (the BeLieVeRHIFi study): a randomised controlled trial. Lancet. 2015 Sep;386(9998):1066-73.

16 Kemp SV, Slebos DJ, Kirk A, Kornaszewska $\mathrm{M}$, Carron K, Ek L, et al.; TRANSFORM Study Team. A Multicenter Randomized Controlled Trial of Zephyr Endobronchial Valve Treatment in Heterogeneous Emphysema (TRANSFORM). Am J Respir Crit Care Med. 2017 Dec;196(12):1535-43.

17 Valipour A, Slebos DJ, Herth F, Darwiche K, Wagner M, Ficker JH, et al.; IMPACT Study Team. Endobronchial Valve Therapy in $\mathrm{Pa}$ tients with Homogeneous Emphysema. Results from the IMPACT Study. Am J Respir Crit Care Med. 2016 Nov;194(9):1073-82.

18 Criner GJ, Sue R, Wright S, Dransfield M, Rivas-Perez H, Wiese T, et al.; LIBERATE Study Group. A Multicenter Randomized Controlled Trial of Zephyr Endobronchial Valve Treatment in Heterogeneous Emphysema (LIBERATE). Am J Respir Crit Care Med. 2018 Nov;198(9):1151-64.

19 Koenigkam-Santos M, de Paula WD, Owsijewitsch M, Wielpütz MO, Gompelmann D, Schlemmer HP, et al. Incomplete pulmonary fissures evaluated by volumetric thin-section CT: semi-quantitative evaluation for small fissure gaps identification, description of prevalence and severity of fissural defects. Eur J Radiol. 2013 Dec;82(12):2365-70.

20 Sciurba FC, Criner GJ, Strange C, Shah PL, Michaud G, Connolly TA, et al.; RENEW Study Research Group. Effect of Endobronchial Coils vs Usual Care on Exercise Tolerance in Patients With Severe Emphysema: The RENEW Randomized Clinical Trial. JAMA. 2016 May;315(20):2178-89. 
21 Slebos DJ, Cicenia J, Sciurba FC, Criner GJ, Hartman JE, Garner JL, et al. Predictors of Response to Endobronchial Coil Therapy in Patients with Advanced Emphysema. Chest. 2019 May;155(5):928-37.

22 Tenda ED, Ridge CA, Shen M, Yang GZ, Shah PL. Role of Quantitative Computed Tomographic Scan Analysis in Lung Volume Reduction for Emphysema. Respiration. 2019; 98(1):86-94.

23 Herth FJF, Kirby M, Sieren J, Herth J, Schirm J, Wood S, et al. The Modern Art of Reading Computed Tomography Images of the Lungs: Quantitative CT. Respiration. 2018;95(1): 8-17.

24 Puhan MA, Chandra D, Mosenifar Z, Ries A, Make B, Hansel NN, et al.; National Emphysema Treatment Trial (NETT) Research Group. The minimal important difference of exercise tests in severe COPD. Eur Respir J. 2011 Apr;37(4):784-90.

25 Jones PW. St. George's Respiratory Questionnaire: MCID. COPD. 2005 Mar;2(1):75-9.

26 Donohue JF. Minimal clinically important differences in COPD lung function. COPD. 2005 Mar;2(1):111-24.
27 Hartman JE, Ten Hacken NH, Klooster K, Boezen HM, de Greef MH, Slebos DJ. The minimal important difference for residual volume in patients with severe emphysema. Eur Respir J. 2012 Nov;40(5):1137-41.

28 Mehta CR, Pocock SJ. Adaptive increase in sample size when interim results are promising: a practical guide with examples. Stat Med. 2011 Dec;30(28):3267-84.

29 Deslée G, Mal H, Dutau H, Bourdin A, Vergnon JM, Pison C, et al.; REVOLENS Study Group. Lung Volume Reduction Coil Treatment vs Usual Care in Patients With Severe Emphysema: The REVOLENS Randomized Clinical Trial. JAMA. 2016 Jan;315(2):17584.

30 Shah PL, Zoumot Z, Singh S, Bicknell SR, Ross ET, Quiring J, et al.; RESET trial Study Group. Endobronchial coils for the treatment of severe emphysema with hyperinflation (RESET): a randomised controlled trial. Lancet Respir Med. 2013 May;1(3):233-40.

31 Klooster K, Ten Hacken NH, Franz I, Kerstjens HA, van Rikxoort EM, Slebos DJ. Lung volume reduction coil treatment in chronic obstructive pulmonary disease patients with homogeneous emphysema: a prospective feasibility trial. Respiration. 2014;88(2):116-25.
32 Slebos DJ, Hartman JE, Klooster K, Blaas S, Deslee G, Gesierich W, et al. Bronchoscopic Coil Treatment for Patients with Severe Emphysema: A Meta-Analysis. Respiration. 2015;90(2):136-45.

33 Makris D, Leroy S, Pradelli J, Benzaquen J, Guenard H, Perotin JM, et al. Changes in dynamic lung mechanics after lung volume reduction coil treatment of severe emphysema. Thorax. 2018 Jun;73(6):584-6.

34 Kloth C, Thaiss WM, Hetzel J, Ditt H, Grosse U, Nikolaou K, et al. Impact of endobronchial coiling on segmental bronchial lumen in treated and untreated lung lobes: correlation with changes in lung volume, clinical and pulmonary function tests. Eur Radiol. 2016 Jul; 26(7):2176-83

35 Deslee G, Leroy S, Perotin JM, Mal H, Dutau $\mathrm{H}$, Bourdin A, et al. Two-year follow-up after endobronchial coil treatment in emphysema: results from the REVOLENS study. Eur Respir J. 2017 Dec;50(6):pii: 1701740.

36 Criner GJ, Sternberg AL. National Emphysema Treatment Trial: the major outcomes of lung volume reduction surgery in severe emphysema. Proc Am Thorac Soc. 2008 May; 5(4):393-405. 